\title{
Power quality survey and harmonic compensation in high power system
}

\author{
Madhukar Waware $^{\mathrm{a}^{*}}$, Pramod Agarwal ${ }^{\mathrm{b}}$ \\ ${ }^{a}$ Department of Electrical Engineering, Walchand College of Engineering, Sangli, India-416415 \\ b Department of Electrical Engineering, Indian Institute of Technology, Roorkee, India-247667
}

\begin{abstract}
In this paper harmonic survey at different high power nonlinear loads is presented. An attempt is made here to record the existing level of harmonic pollution present in the Indian system for the investigation. In modern industrial sector many controlled processes are being carried out at high power and high voltage levels. A power quality survey is carried out in the industry, where high power AC drive is used. A survey at substation is also conducted to know the harmonic level present at the distribution level. Implementation of shunt active power filter (APF) in high voltage system requires high rating transformer which increases the losses and cost. But application of multilevel inverter in active filters eliminates use of bulky and high cost transformer and also improves the performance. Simulated results prove the effective elimination of harmonics with multilevel inverter in high voltage power system without use of transformer.
\end{abstract}

Keywords: Power quality, multilevel inverter, active power filters

\section{Introduction}

The alternating current systems have blown utility of electrical power both for the concentrated as well as distributed loads. Linear loads draw sinusoidal current, when sinusoidal voltage is applied across it. But this is no longer the case with modern electric power systems. Massive use of the nonlinear devices has led to distortion of voltage and current waveforms. As a consequence, the issue of power quality has become important. Both the electric utility and end-users of electric power are becoming increasingly concerned about the quality of electric power. The applications of advanced technologies in industrial sectors include power semiconductor systems which are designed using fast switching power semiconductor devices such as phase controlled or uncontrolled rectifiers, inverters, AC voltage controllers and cycloconverters. High voltage converters are used in high voltage drives, electric traction and high voltage DC transmission (HVDC).

Commercial facilities such as office complex, department stores, hospitals, Internet data centers and others are dominated with energy efficient fluorescent lighting with electric ballasts; which employs switch mode power supply; uninterruptible power supply, personal computers, printers etc. are seen as nonlinear loads by the power system [1]. Nonsinusoidal currents propagate throughout the power system, causing voltage drop across the impedance of transmission lines and transformers. Thus the voltage at the point of common coupling (PCC) is no longer sinusoidal, but it is distorted. The quantum of voltage distortion depends on the line impedance and the magnitude of current. When several customers or users share a common power line, the voltage distortion produced due to harmonic current injection by one user can adversely affect the quality of power supplied to others [2].

Harmonics are responsible for increased system losses, heating of equipment and reduction in its useful

\footnotetext{
* Manuscript received August 3, 2013; revised October 15, 2013.

Corresponding author. Tel.: 91-7507427935; E-mail address: waware.madhukar@gmail.com
} 
life, mal-operation of protective devices, failure of reactive power compensating capacitors, and interference with control and communication circuits. Occurrence of parallel resonance between the supply system reactance and power factor improvement capacitors are also not uncommon [3] [4]. This necessitates an effective elimination of harmonics both for the utilities and the end users [5].

In this paper harmonic survey carried out in high power applications is presented. Such survey will provide a fairly better idea about harmonic problem and its location. An attempt is made here to record the existing level of harmonic pollution present in the Indian system for the investigation. The voltage and current waveforms of some commonly used loads and their harmonics have been measured. Total harmonic distortion (THD) is used as an index to identify the effects of different nonlinear loads. The possible solutions for harmonics in high power applications are discussed. Simulation results show that use of multilevel inverter based active power filter eliminates harmonics in high voltage high system effectively.

\section{Power Quality Survey}

A power quality survey is carried out in the industry, where high power AC drive is used. A survey at substation is also conducted to know the harmonic level present at the distribution level. In commercial complex where fluorescent tubes and compact florescent lamps (CFLs) are being used as part of energy conservation program, but introduces the harmonics in the system. While recording the harmonics and waveforms by power analyzer, 1, 2 and 3 notations are used for phase A, B and C respectively.

\subsection{Power quality at starch industry}

Sahyadri Starch is the starch manufacturing company at M.I.D.C Miraj, Maharashtra, India. Maize starch is produced by the wet milling process, which involves grinding of softened maize and separation of corn oil seeds (germs), gluten (proteins), fibers (husk) and finally pure starch. The blowers are used for the separation of starch after grinding. Controlled air flow is required for proper separation and good quality of starch. The control is achieved with the help of AC drive based on the quantity of starch and temperature of the medium. A three-phase drive of $110 \mathrm{KW}, 440 \mathrm{~V}$ (line-line) is used for this application. Three-phase current waveforms and corresponding harmonic contents are recorded and shown in Fig. 1 for phase A only. The voltage and current waveforms are shown in Fig. 2 (a). Harmonic measurements show that the voltage harmonics are less, but, current waveforms are highly distorted. The THD for phase $\mathrm{A}, \mathrm{B}$ and $\mathrm{C}$ are $52.2 \%, 53.6$ and $45.1 \%$. It is observed that 5 th and 7 th harmonics are the dominating components and thus adjustable speed drives generate high value of distortion. The active, reactive power and power factor are also recorded in Fig. 2 (b). It is observed that the nonlinear load draws the reactive power, resulting in lowering the power factor to 0.877 . This creates a concern for power quality and thus necessitates suitable measures for compensation of reactive power drawn by the load and corrections of harmonics.

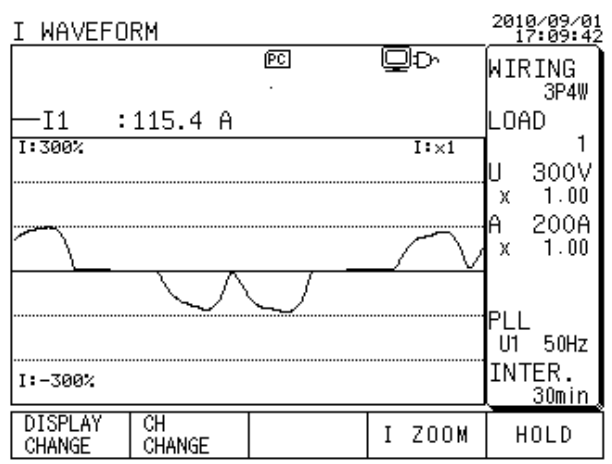

(a)

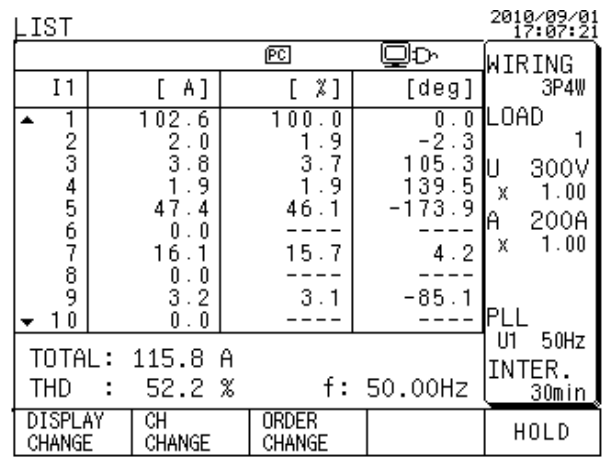

(b)

Fig. 1 (a) Waveform and (b) harmonic spectrum of input current of phase A AC drive at starch industry . 


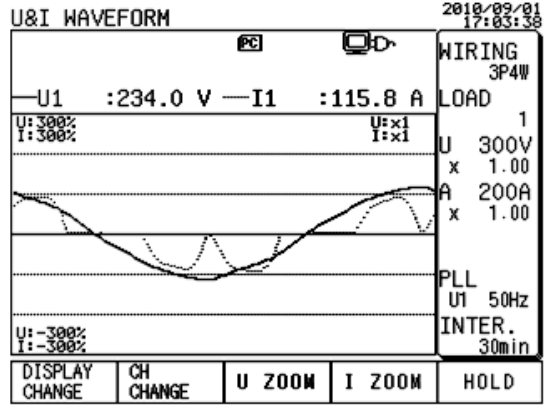

(a)

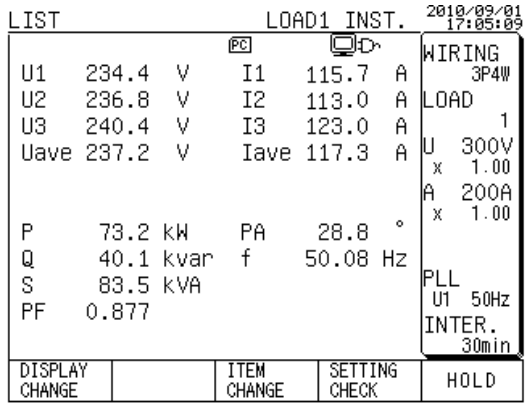

(b)

Fig. 2 (a) Waveforms and (b) magnitudes of voltage and current of phase A at starch industry.

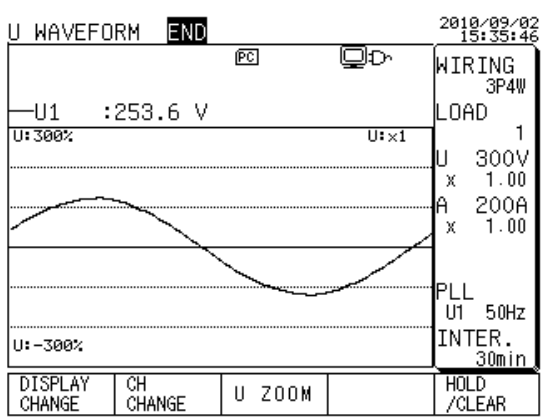

(a)

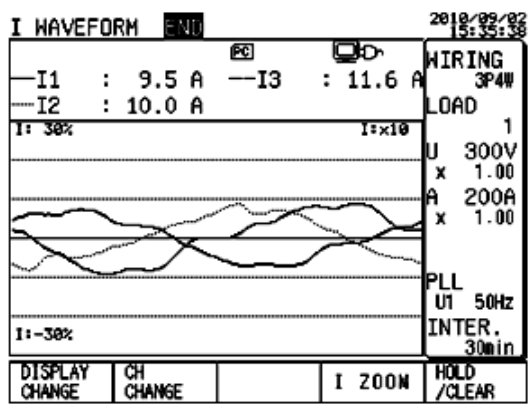

(b)

Fig. 3 Power quality survey at battery charging room at substation (a) voltage waveform and (b) three-phase current waveforms.

\begin{tabular}{|c|c|c|c|c|}
\hline ST & ENI & & & $\begin{array}{r}2818: 09 \\
15: 34\end{array}$ \\
\hline & & 중 & 말 for & WIRI \\
\hline I1 & $\begin{array}{lll} & \text { A }\end{array}$ & {$\left[\begin{array}{ll}{[x]} \\
\end{array}\right.$} & [deg] & $3 P 4 \|$ \\
\hline $\begin{array}{|ll|}\boldsymbol{A} & 1 \\
\end{array}$ & $\begin{array}{l}9.4 \\
0.9\end{array}$ & $\begin{array}{r}100.0 \\
9.8\end{array}$ & $\begin{array}{r}0.0 \\
132.3\end{array}$ & LOAD \\
\hline $\begin{array}{l}3 \\
3 \\
4\end{array}$ & $\begin{array}{l}0.0 \\
0.0\end{array}$ & --- & - & $\begin{array}{ll}u & 300 \mathrm{v} \\
x & 1\end{array}$ \\
\hline & 0.0 & --- & --- & {$\left[\begin{array}{lll}x & 1 & 0.00 \\
A^{2} & 0\end{array}\right.$} \\
\hline & 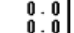 & ----- & $=---1$ & $\begin{array}{ll}x \\
\times & 1.00\end{array}$ \\
\hline 8 & 0.0 & ---- & ---1 & \\
\hline-10 & 0.0 & $-\cdots-$ & $-\cdots$ & \\
\hline TOTAL & $9.5 \mathrm{f}$ & & ER. \\
\hline THD & 9.8 & & & \\
\hline $\begin{array}{l}\text { DISPLAY } \\
\text { CHANGE }\end{array}$ & CH & \multicolumn{2}{|c|}{$\begin{array}{l}\text { f: } 50.24 \mathrm{~Hz} \\
\text { OPDER }\end{array}$} & $\begin{array}{l}\text { HOLD } \\
\text { CLLEAR }\end{array}$ \\
\hline
\end{tabular}

Fig. 4 Power quality survey at battery charging room at substation-current harmonic spectrum in phase A.

\subsection{Power quality at substation and distribution lines}

A survey of voltage and current harmonics present in the distribution system at Battery Charging Room at 110/33KV Substation Vishrambag, Sangli, Maharashtra, India, is carried out. The voltage waveform which is sinusoidal is shown in Fig. 3 (a) and the nonsinusoidal current waveforms are shown in Fig. 3 (b). Voltage distortion was observed less than 1-2\%, but current distortion was significant. The THD in phase $\mathrm{A}$ is $9.8 \%$ as shown in Fig. 4.

\subsection{Power quality in commercial complex}

Harmonic survey is conducted in a commercial complex at Sangli, Maharashtra, which have many shops of diverse products and services with majority of electronic gadgets. In commercial complex fluorescent lamp and electronic ballasts are used widely due to their high efficiency. The relationship between voltage across and current through a fluorescent lamp is nonlinear due to characteristic of the electric arc, which is responsible for illumination. The electronic ballast consists of half bridge inverter 
and an LC filter, which is responsible for nonlinear characteristics of the lamp. Fig. 5 shows the different power components and power factor at commercial complex. The current waveform and harmonic content for phase $\mathrm{C}$ is shown in Fig. 6. The maximum current THD observed is $18.3 \%$. Thus, the use of modern equipments in commercial complex, deteriorate the power quality and it necessitates corrective action to improve the power factor and harmonic compensation at such complexes.

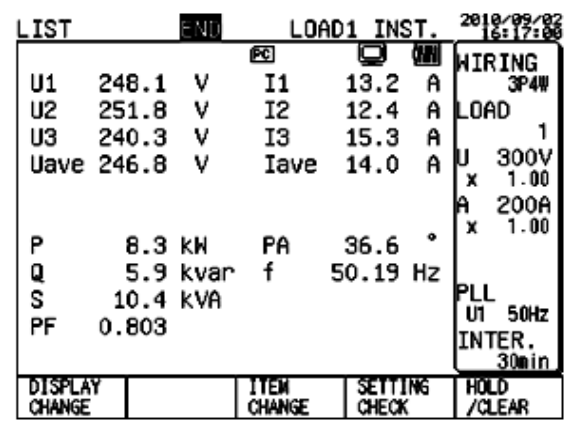

Fig. 5. Voltage, current and power at commercial complex.

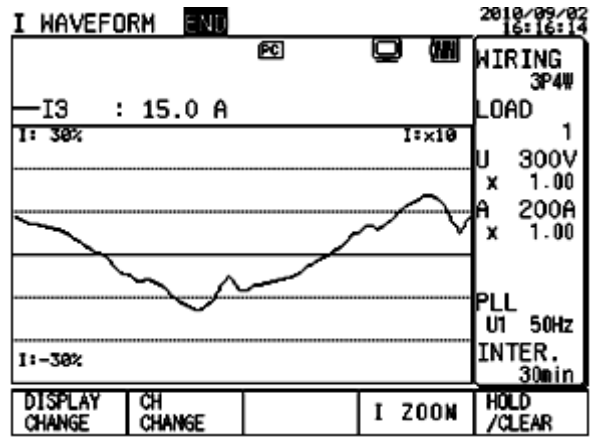

(a)

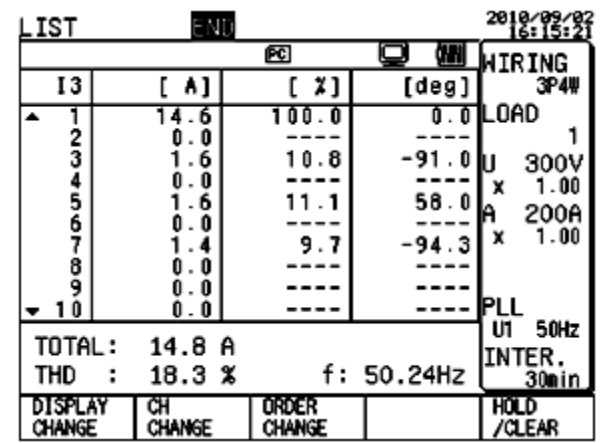

(b)

Fig. 6 Power quality survey at commercial complex: (a) current waveform and (b) its harmonic spectrum of phase C.

Survey of harmonics content at high power drives in industry, high voltage distribution system and in commercial complex is carried out with an objective to know the existing level of harmonic distortion present in the system. It is observed that generally the voltage distortion is recorded to be within the acceptable limit of maximum THD. However the current distortion is found to be around $52.2 \%$ in the industrial sector with adjustable drives. Increasing use of such loads may result in serious deterioration of power quality and thus it needs to be controlled, so that THD is within IEEE limit of 5\%.

\section{Harmonic Compensation Techniques}

Compensation of current harmonics injected by nonlinear load is required to be done nearest to the load terminal so that harmonic current do not flow into the system [6]. It reduces to a great extent the amount of distortion in the voltage at PCC. There are various methods to compensate harmonics. The conventional methods are passive filters and APFs.

\subsection{Passive filters}

Despite simplicity and low cost of passive filters their use is limited as these are tuned to particular frequency and only that harmonic is eliminated, filtering characteristics are dependent on source impedance which is not accurately known and also varies with changes in configuration of power system during its operation and at particular frequency resonance may occur between the source impedance and shunt passive filter, resulting in harmonic amplification. 


\subsection{Active power filters}

Active power filters (APFs) are seen as a viable alternative over classical passive filter and reactive power compensation of non-linear loads [7]. Fig. 7 shows the basic compensation principle of the Shunt APF. In general the APFs are Pulse Width Modulated (PWM) inverters with capacitor or inductor on its side. The PWM inverter switches are controlled such that it supply a compensating current $i_{c}$ and cancels current harmonic on the AC side by generating harmonics opposite to the load harmonics [8]. This makes the source current $i_{s}$ almost sinusoidal which may be in phase or phase displaced with mains voltage, based on design of control algorithm of the filter [9],[10]. The design can cater to the requirements of either both harmonic and reactive power compensation or only harmonic compensation.

Remarkable progress in the capacity and switching speed of solid state, self commutating power semiconducting devices such as power MOSFET, IGBTs, IGCTs and parallel progress in processers and high speed digital signal processing (DSP) has made APFs more effective and efficient to eliminate current harmonics generated by non-linear loads in low voltage system.

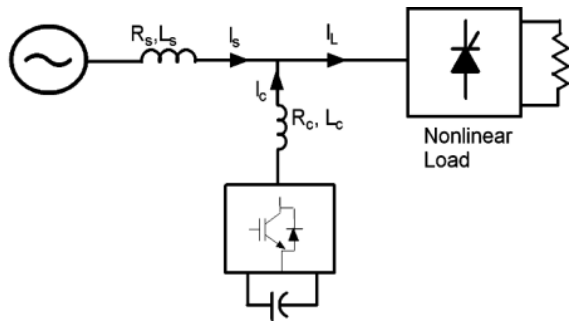

Fig. 7 Basic block diagram of APF.

Many technical papers related with APF have been presented during last two decade, most of them dealt with their principles of operation, design of control schemes and presentation of different techniques to calculate the reference signals required by the control scheme and do not address its limitations in medium and high voltage application.

In modern industrial sector many controlled processes are being carried out at high voltage levels. The range of induction motor drives has reached up to $20 \mathrm{MW}$ for supply voltages from $3.3 \mathrm{kV}$ to $13.8 \mathrm{kV}$ of $50 \mathrm{~Hz}$ or $60 \mathrm{~Hz}$. The large size passive filters for different harmonic components are used in high voltage DC (HVDC) systems which result in high space requirement and high cost. Alternatively, application of APFs in high voltage system is gaining importance and interest of researchers [11]. The conventional active filters have limitations in medium and high voltage applications due to semiconductor's reverse voltage rating constraint, high losses caused by switching high voltage and high current, consequent high $d v / d t$, adversely affect the communication system due to EMI as well as insulation degradation in electronic and electrical systems. The commutation frequencies increase the losses directly affecting the efficiency of the active filter.

APFs can be used in high voltage system in two ways. In first method series connected semiconductor switches are used but, this configuration faces problems of unbalanced static and dynamic voltage sharing due to deviations of device characteristics and drive circuits. It further, requires large number of snubber components which cause additional losses and adversely affect reliability of the system. The second way is to connect APF through step up transformer. In this method the volt-ampere (VA) rating of transformer is much higher than the rms VA rating of system due to reactive power of harmonics. The use of transformer also causes difficulties in control due to DC magnetizing and surge overvoltage problems causing saturation of the transformers in transient states, thus, making overall system more bulky and costly.

\section{MLI Based APF For High Voltage Systems}

Development of high voltage inverters based on MLIs has attracted the attention of power electronics 
community. The characteristic of these converters is to generate a waveform using several voltage levels and thus causing a very low harmonic content associated with switching of devices. MLI includes an array of power semiconductors and capacitors. The commutation of the switches facilitates summation of capacitor voltages, providing high output voltage without the use of transformer, and without additional stressing on power semiconductors.

There are three basic types of MLIs, viz. diode clamped, flying capacitor and cascade multilevel. Cascade MLIs are increasingly being adopted in high power applications due to its modular structure which make easy to design, assemble and control of other types of MLI [12].

In operation of MLI based APF, the harmonic component of load current is derived through harmonic detection circuit and used it with opposite polarity as the reference compensating current. Switching signals for MLI are generated such that AC side output current of APF follows the reference current closely and provides the harmonic current of the load to make source current nearly free from harmonics. This application does not require active power output from the inverter; therefore separate source for each converter bridge is not required.

The APF also draws small power from source to compensate the switching and capacitor losses in the APF. DC voltage of each converter should be balanced for proper compensation. The capacitor voltages are sensed and compared with the reference voltage. The error is processed in a controller to generate loss component of APF which is used to generate the reference signal of APF [13],[14].

The power circuit diagram of five-level MLI based APF is shown in Fig. 8. The MLI based APF system is developed in MATLAB SIMULINK and following parameters are selected for simulation.

$$
\begin{array}{lllll}
V_{s}=11000 \mathrm{~V}, & f=50 \mathrm{~Hz} & R_{s}=0.1 \Omega, & L_{s}=0.5 \mathrm{mH} & R_{c}=0.5 \Omega, \\
L_{c}=4 \mathrm{mH} & V_{d c, \text { ref }}=6500 \mathrm{~V}, & C_{d c}=5000 \mu \mathrm{F} & R_{\text {Load }}=100 \Omega & L_{\text {load }}=40 \mathrm{mH}
\end{array}
$$

The simulation results are shown in Fig. 9. The source voltages, load currents are sensed and reference source currents are generated by using $p-q$ theory [14] and gating pulses are generated by carrier phase shifted PWM (CPS-PWM) [16]. The load current $i_{L a}$ is nonsinusoidal with THD of $23.94 \%$. APF injects compensating current, so that source current becomes sinusoidal with THD of 1.94\% as shown in Fig. 10. In five-level MLI, voltage across each capacitor is nearly half of supply line voltage. This reduces the rating of switching device which is an important advantage to support use of MLI for APF in high voltage system. Further the voltage waveform on AC side of MLI is of reduced THD as compared to two-level inverter.

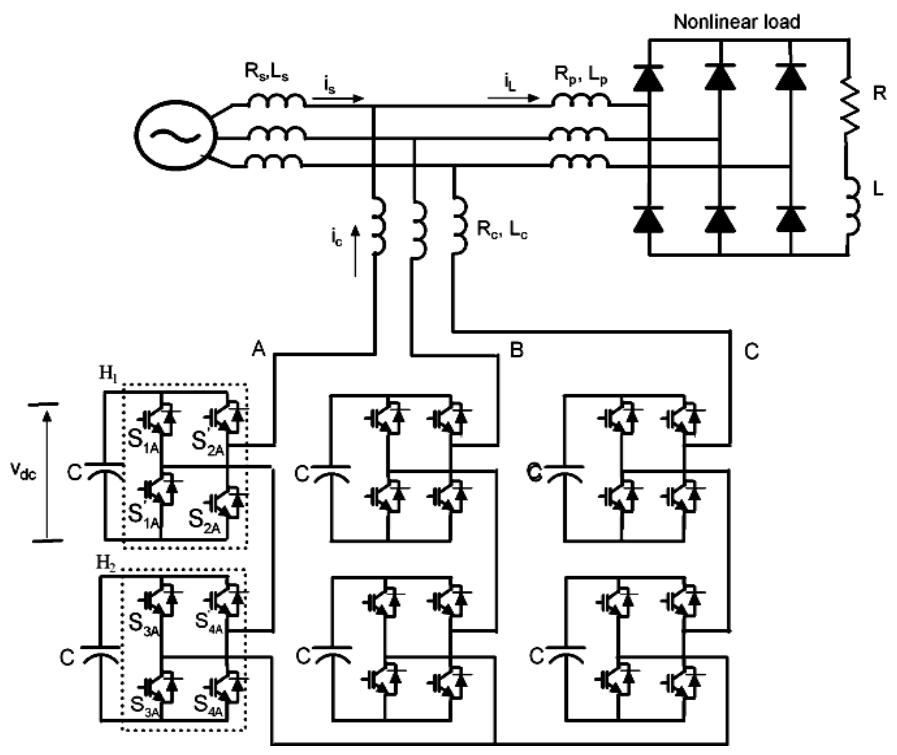

Fig. 8 MLI based APF. 

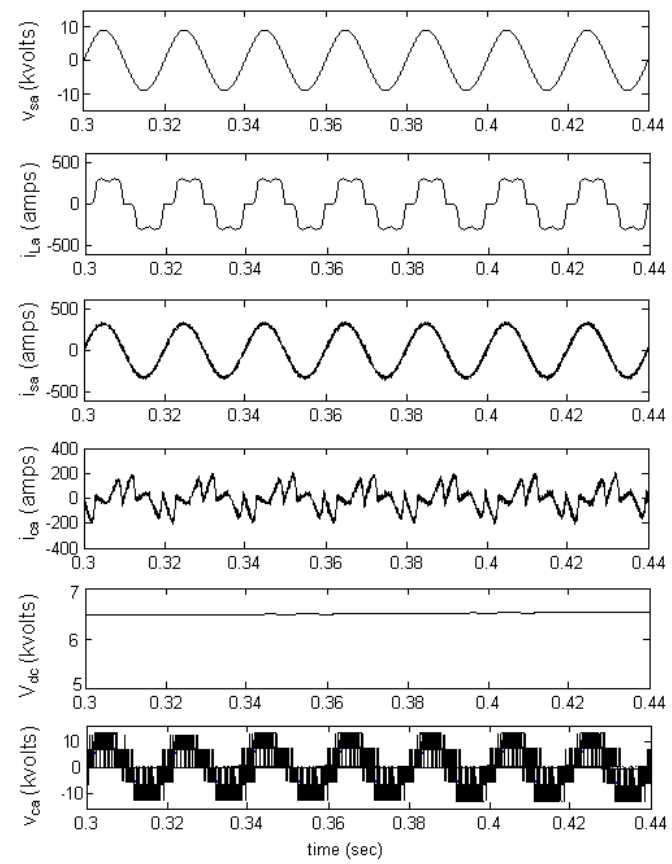

Fig. 9 Source voltage $\left(v_{s b}\right)$, load current $\left(i_{L b}\right)$, compensated source current $\left(i_{s b}\right)$, APF current $\left(i_{c b}\right)$ and MLI AC side voltage.

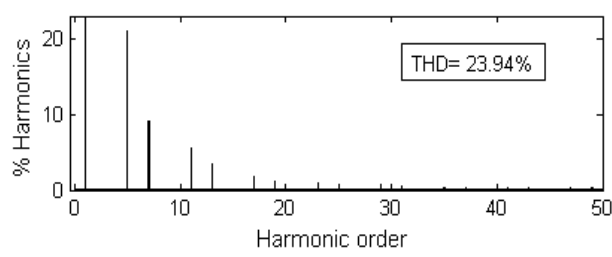

(a)

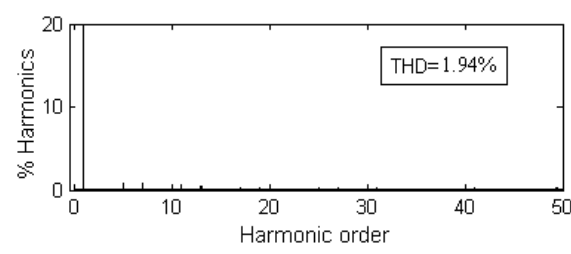

(b)

Fig. 10 Frequency spectrum of source current, (a) before compensation and, (b) after compensation

\section{Conclusion}

In this paper a survey of harmonics content at high power drives in industry, high voltage distribution system and in commercial complex is presented. It is observed that the voltage distortions are within 1$2 \%$, which is well below the IEEE standard limit of $5 \%$, but current distortion is found to be around $52.2 \%$ in the industrial sector with adjustable drives high range, which should eliminated near customer end. The conventional APFs are effective in low voltage applications, but in high voltage systems, they have limitations and make system bulky and of high cost. Use of multilevel inverter for APF in high voltage system eliminates use of high cost transformer. Simulated results verify that five level MLI based APF can compensate harmonics without use of transformer correctly and validly.

\section{References}

[1] Arrilaga J., Bardely D. A. and Bodger P. S., Power System Harmonic, John Wiley and Sons, London, July 1985.

[2] Dugan R. C., McGranagha M. F. and Beaty H. W., Electrical Power Systems Quality, New York, McGraw-Hill, 1996.

[3] Rice D. E. Adjustable speed drivers and power rectifier harmonics-their effects on power system components. IEEE Transaction on Industry Applications, 1986; IA-22 (1):161-177.

[4] Shipp D. D. Harmonic analysis and suppression for electrical systems supplying static power converters and other nonlinear loads. IEEE Transaction. on Industry Applications, 1979;IA-15:5. 
[5] IEEE Recommended practices and requirements for harmonic control in power system, IEEE Std. 519-1992, IEEE, New York, 1993.

[6] Bhavshar T. and Narayanan G. Harmonic analysis of advanced bus-clamping PWM techniques. IEEE Trans. on Power Electronics, 2009;24(10):2347-2352.

[7] Akagi H. Trends in active power line conditioners. IEEE Transaction on Power Electronics, May 1994;9(3):263-268.

[8] Salam Z., Cheng T. P. and Jusoh A. Harmonics mitigation using active power filter: A technological review. ELEKTRIKAUTM Journal of Electrical Engineering, 2006;8(2):17-26.

[9] Singh B., Chandra A. and Al-Haddad K. An improved control algorithm of shunt active filter for voltage regulation, harmonic elimination, power factor correction and balancing of non-linear Loads. IEEE Transaction on Power Electronics, May 2000;15(3):495-506.

[10] Salehifar M., Shoulaie A. Harmonic elimination in single phase systems using a high performance hybrid active filter. International Review of Electrical Engineering(IREE), 2011;6(1):89-97.

[11] Massoud A. M., Finney S. J. and Williams B. W. Three phase three-wire, five level cascaded shunt active filter for power conditioning, using two different space vector modulation techniques. IEEE Transaction on Power delivery, 2007;22(4)23492361.

[12] Lai J. S and Peng F. Z. Multilevel converters-A new breed of power converters. IEEE Transaction on Industry Applications, 1996;32(3):509-517.

[13] Peng F. Z. and Mckeever J. W. A power line conditioner using cascade multilevel inverter for distribution systems. IEEE Transaction on Industry Application, November 1998;43(6):1293-1298.

[14] Lopez M. G., Moran L. T., Espinoza J. C. and Dixon J. C. Performance analysis of a hybrid symmetric multilevel inverter for high voltage active power filter applications. in Proc. of IEEE Industrial Electronics Society Annual Conference, 2003:10501055.

[15] Peng F. Z. and Lai J. S. Generalized instantaneous reactive power theory for three-phase power systems. IEEE Transaction on Instrumentation and Measurement, February 1996;45(1):293-297.

[16] McGrath B. P. and Holmes D. G. Opportunities for harmonic cancellation with carrier-based PWM for two-level and multilevel Cascaded Inverters. IEEE Tranaction on Industry Applications, 2001;37(2):574-582. 